\title{
A ping-pong ball in left atrium
}

\author{
Akshyaya Pradhan, Sameer Ganpat Vankar, Pravesh Vishwakarma, Rishi Sethi
}

Department of Cardiology, Chatrapati Shahu Maharaj Medical University, Lucknow, Uttar Pradesh, India

\section{Correspondence to} Dr Sameer Ganpat Vankar, samvan7@yahoo.co.in

Accepted 18 December 2017

\section{DESCRIPTION}

Rheumatic heart disease (RHD) is much prevalent in low/middle-income country like India with the prevalence ranging from 0.2 to $1.1 / 1000$ for RHD and from 0.0007 to $0.2 / 1000$ for rheumatic fever. ${ }^{1}$ Factors that precipitate the formation of clot are atrial fibrillation (AF) rhythm, left atrial (LA) size, duration of symptoms, advanced age and severity of mitral stenosis (MS). ${ }^{2}$ The prevalence of LA clot in patients with MS is $26 \%$ in the AF group and $13.5 \%$ in the normal sinus rhythm group. ${ }^{3}$ The risk of thromboembolism is $9-14 \%$ of patients suffering from RHD. ${ }^{4}$ Anticoagulation (vitamin $\mathrm{K}$ antagonist or heparin) is indicated in patients with MS with (1) AF (paroxysmal, persistent or permanent) or (2) prior embolic event or (3) a LA thrombus. ${ }^{6}$

We present a case of a 30-year-old man, a known case of RHD who had balloon mitral valvotomy (BMV) 10 years ago. He presented with increase in frequency of palpitation and dyspnoea on exertion (New York Heart Association (NYHA) class III) for the last 5 months. The patient was in sinus rhythm

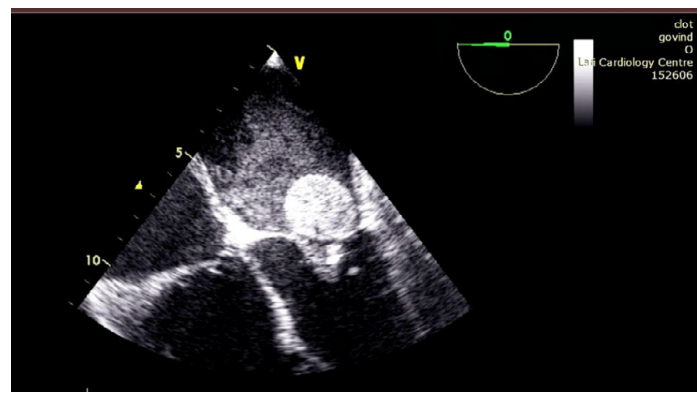

Figure 1 Transoesophageal echocardiography at mid oesophagus showing four-chamber view with $5.2 \times 7.2 \mathrm{~cm}$ large left atrial clot.

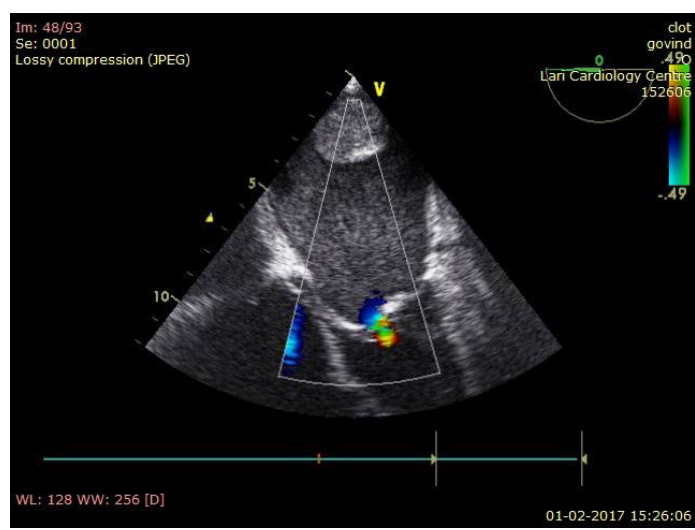

Video 1 Transthoracic echocardiography parasternal long-axis view showing the large freely mobile thrombus bouncing to and fro into the mitral apparatus like a pingpong ball.

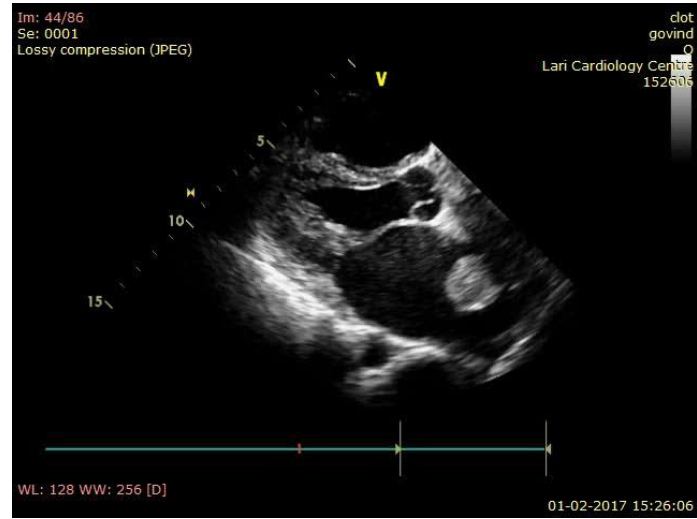

Video 2 Transoesophageal echocardiography mid oesophagus four-chamber view showing large left atrial (LA) thrombus bouncing against the mitral apparatus like a ping-pong ball. Also note the LA smoke in the background.

and was receiving beta-blocker and diuretic. His transthoracic (TT) 2D echocardiography (ECHO) revealed moderate mitral valve restenosis with mitral valve area reduced to $1.1 \mathrm{~cm}^{2}$ (planimetry method) and $1.2 \mathrm{~cm}^{2}$ (pressure half time method). The peak and mean gradient across the mitral valve were 11 and $6 \mathrm{~mm}$ $\mathrm{Hg}$, respectively. He also had trivial mitral regurgitation and left ventricular ejection fraction was $65 \%$. LA size was $5.2 \times 7.2 \mathrm{~cm}$. Both TT and transoesophageal (TOE) ECHO revealed a large freely mobile LA clot measuring $2.2 \mathrm{~cm}$ in diameter. The large LA clot was seen falling intermittently into the mitral apparatus to be hit back again by the mitral leaflet (figure 1, video 1 , video 2). The large thrombus in LA gave appearance similar to the ping-pong ball moving to and fro in the mitral apparatus. Patient was not on any anticoagulation or antiplatelets at the time of diagnosis of LA clot. Patient was started on oral anticoagulation (warfarin $2 \mathrm{mg}$ once a day and gradually increased to achieve

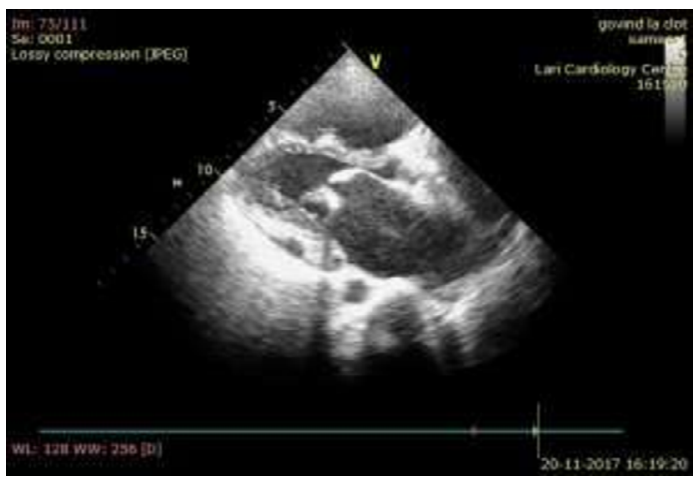

Figure 2 Transthoracic echocardiography parasternal long-axis view showing dense left atrial smoke at 8-month follow-up visit. 
therapeutic international normalised ratio []between 2 and 3) as he was not willing for surgical removal of thrombus and injectable anticoagulation. At his follow-up visit 1 month later, the patient was in NYHA class II with INR measuring 2.2 on $5 \mathrm{mg}$ of warfarin. His review TT 2D ECHO done at 8 months follow-up visit revealed LA clot was resolved; however, spontaneous echo contrast was present (figure 2). TOE ECHO was not done as patient did not consent and he was continued on oral anticoagulation.

This case emphasises on the importance of ECHO immediately prior to the planned BMV procedure. It also highlights the mismatch between large LA thrombus and stenosed mitral valve which prevented thrombus from undergoing systemic embolisation.

\section{Learning points}

- Importance of transoesophageal echocardiography immediately prior to balloon mitral valvotomy .

- Large freely mobile thrombus need not present with thromboembolic phenomenon due to mismatch in the size between the large left atrial thrombus and mitral valve apparatus protecting it.
Contributors All the authors contributed to discussion, comments and editing the case report. AP was the cardiologist in charge and initiated and edited the manuscript. SGV: ECHO recording, drafting and finalising the manuscript. PV: expert comment and critical analysis of the manuscript. RS: overall concept and final finishing touch to the manuscript.

Competing interests None declared.

Patient consent Obtained.

Provenance and peer review Not commissioned; externally peer reviewed.

(C) BMJ Publishing Group Ltd (unless otherwise stated in the text of the article) 2018. All rights reserved. No commercial use is permitted unless otherwise expressly granted.

\section{REFERENCES}

1 Shah B, Sharma M, Kumar R, et al. Rheumatic heart disease: progress and challenges in India. Indian J Pediatr 2013;80(Suppl 1):77-86.

2 Goswami KC, Yadav R, Rao MB, et al. Clinical and echocardiographic predictors of left atrial clot and spontaneous echo contrast in patients with severe rheumatic mitral stenosis: a prospective study in 200 patients by transesophageal echocardiography. Int J Cardiol 2000;73:273-9.

3 Saidi SJ, Motamedi MH. Incidence and factors influencing left atrial clot in patients with mitral stenosis and normal sinus rhythm. Heart 2004;90:1342-3

4. Wood P. An Appreciation of Mitral Stenosis. Brit. med Diseases of the Heart and Circulation. 2nd ed 1954;7:1051.

5 Wood P. Diseases of the Heart and Circulation. 2nd edn, 1956:525.

6 Nishimura RA, Otto CM, Bonow RO, et al. 2014 AHA/ACC Guideline for the Management of Patients With Valvular Heart Disease: executive summary: a report of the American College of Cardiology/American Heart Association Task Force on Practice Guidelines. Circulation 2014;129:2440-92.

Copyright 2017 BMJ Publishing Group. All rights reserved. For permission to reuse any of this content visit

http://group.bmj.com/group/rights-licensing/permissions.

BMJ Case Report Fellows may re-use this article for personal use and teaching without any further permission.

Become a Fellow of BMJ Case Reports today and you can:

- Submit as many cases as you like

- Enjoy fast sympathetic peer review and rapid publication of accepted articles

- Access all the published articles

Re-use any of the published material for personal use and teaching without further permission

For information on Institutional Fellowships contact consortiasales@bmjgroup.com

Visit casereports.bmj.com for more articles like this and to become a Fellow 